Keywords: human oral squamous cell carcinoma; polyphenols; cochlea; otoprotection; heme oxigenase-1; chemotherapeutic adjuvant; pro-/antioxidant effect

\title{
Molecular targets for anticancer redox chemotherapy and cisplatin-induced ototoxicity: the role of curcumin on PSTAT3 and Nrf-2 signalling
}

\author{
A R Fetoni ${ }^{1,3}$, F Paciello ${ }^{1,3}$, D Mezzogori ${ }^{2}$, R Rolesi ${ }^{1}$, S L M Eramo ${ }^{2}$, G Paludetti ${ }^{1,4}$ and D Troiani ${ }^{\star, 2,4}$ \\ ${ }^{1}$ Department of Head and Neck Surgery, Università Cattolica, School of Medicine, Largo F Vito 1, Rome 00168, Italy and ${ }^{2}$ Institute \\ of Human Physiology, Università Cattolica, School of Medicine, Largo F Vito 1, Rome 00168, Italy
}

Background: In oncology, an emerging paradigm emphasises molecularly targeted approaches for cancer prevention and therapy and the use of adjuvant chemotherapeutics to overcome cisplatin limitations. Owing to their safe use, some polyphenols, such as curcumin, modulate important pathways or molecular targets in cancers. This paper focuses on curcumin as an adjuvant molecule to cisplatin by analysing its potential implications on the molecular targets, signal transducer and activator of transcription 3 (STAT3) and NF-E2 p45-related factor 2 (Nrf-2), in tumour progression and cisplatin resistance in vitro and the adverse effect ototoxicity in vivo.

Methods: The effects of curcumin and/or cisplatin treatment have been evaluated in head and neck squamous cell carcinoma as well as in a rat model of cisplatin-induced ototoxicity by using immunofluorescence, western blot, and functional and morphological analysis.

Results: This study demonstrates that curcumin attenuates all stages of tumour progression (survival, proliferation) and, by targeting PSTAT3 and Nrf-2 signalling pathways, provides chemosensitisation to cisplatin in vitro and protection from its ototoxic adverse effects in vivo.

Conclusions: These results indicate that curcumin can be used as an efficient adjuvant to cisplatin cancer therapy. This treatment strategy in head and neck cancer could mediate cisplatin chemoresistance by modulating therapeutic targets (STAT3 and Nrf2) and, at the same time, reduce cisplatin-related ototoxic adverse effects.

Platinum-based agents, such as cisplatin, form the mainstay of currently used chemotherapeutic regimens for several malignancies (Armstrong et al, 2006; Galluzzi et al, 2012). Notwithstanding the immense therapeutic success associated with partial responses or disease stabilisation, the main limitations to the clinical usefulness of cisplatin are the incidence of chemoresistance and its adverse side effects (Galluzzi et al, 2012). Frequently, patients with relapsed or recurrent disease present resistance to cisplatin (Jacobs et al, 1992; Cullen et al, 2003) and the debilitating side effects such as progressive irreversible ototoxicity (Langer et al, 2013) characterise further major limitations to cisplatin dose escalation. Cisplatin causes a bilateral, symmetric high-frequency hearing loss, often accompanied by tinnitus, as the dose or number of treatments increase; this permanent impairment is responsible for communicative disorders harming further the quality of life of cancer patients (Rybak et al, 2009; Langer et al, 2013; Fetoni et al, 2014). Research addressed to overcome cisplatin limitations has been focused on the development, as an adjuvant therapy, of safe

\footnotetext{
*Correspondence: Professor D Troiani; E-mail: d.troiani@rm.unicatt.it

${ }^{3}$ These authors contributed equally to this work.

${ }^{4}$ The last two authors share senior authorship.
}

Revised 1 September 2015; accepted 16 September 2015; published online 15 October 2015

(C) 2015 Cancer Research UK. All rights reserved 0007 - 0920/15 
molecules able to counteract chemotherapy-associated organ toxicity and to promote tumour toxicity and chemosensitisation. It is now widely accepted that: (a) cisplatin apoptogenicity depends on the formation of ROS and that apoptogenic oxidative stress is the crucial mechanism of both cisplatin-induced cancer cell death (Berndtsson et al, 2007) and damage to vulnerable normal cells (Wondrak, 2009); (b) one of the major systems used by both normal and cancerous cells to counteract oxidative insult is the NF-E2 p45-related factor 2 (Nrf-2) transcriptionally regulated program (Hayes and McMahon, 2009; Wondrak, 2009; Singer et al, 2015); (c) JAK-STAT (Janus kinase-STAT) pathway contributes to tumour cell proliferation and survival, tumour invasion and angiogenesis (Johnston and Grandis, 2011; Yu et al, 2014). Thus, the identification of adjuvant redox therapeutics targeting Nrf-2 and STAT3 constitutes the most rational approach for prevention of chemoresistance and of chemotherapy-associated organ toxicity.

As adjuvant chemotherapeutics, selective pro-oxidant redox intervention that substantially increases cellular ROS and modulates specific redox-sensitive targets can be achieved using small-molecule electrophiles containing a Michael acceptor pharmacophore contained in natural products (Wondrak, 2009). Indeed, nutraceuticals have gained notable interest as viable candidates and the polyphenol curcumin has been studied for the past few decades, with encouraging outcomes, for the antinflammatory, antioxidant, antiproliferative and preventive actions (Aggarwal et al, 2004; Thangapazham et al, 2006; Strimpakos and Sharma, 2008; Goel and Aggarwal, 2010; Zhou et al, 2011). Curcumin is able to influence multiple intracellular pathways and its pro-oxidant or antioxidant effects depend, however, on the concentration of the compound as recently demonstrated by our group in cisplatin-induced ototoxicity (Fetoni et al, 2014). Curcumin is considered a potential hormetin, a coinducer at low doses of heat-shock protein and a direct inducer of heme oxygenase-1 (HO-1), a well-known marker of intracellular stress defence system, and at high doses a cellular growth inhibitor (Calabrese et al, 2008; Demirovic and Rattan, 2013).

On such basis, this research was conceived to explore the prooxidant potential of curcumin as a chemotherapeutic adjuvant targeting in vitro the transcription factors involved in tumour progression and cisplatin resistance, STAT3 and Nrf-2, and the antioxidant curcumin activity by analysing in vivo the protective molecular changes in a model of chemotherapy organ toxicity to further investigate the role of the $\mathrm{Nrf}-2 / \mathrm{HO}-1$ defence system in healthy cells undergoing a stressful condition. Namely, the combinatorial strategy was tested in: (1) the head and neck squamous cell carcinoma (HNSCC) that represents a significant clinical problem and unsatisfactory long-term survival of patients (Camacho-Alonso et al, 2013) and (2) the in vivo model of cisplatin-induced ototoxicity, a well-known adverse effect frequently associated with head and neck cancer treatments. Finally, to distinguish between the pro-oxidant and antioxidant curcumin effects and to mimic a possible treatment dosage to be reached in systemic tissues, we used, both in in vitro and in vivo experiments, different curcumin doses considering that the therapeutic use of curcumin has been limited owing to its poor bioabsorption (Kumar et al, 2014; Prasad et al, 2014).

\section{MATERIALS AND METHODS}

Chemicals. Common laboratory chemicals were from SigmaAldrich (Milan, Italy), unless differently stated. Antibodies used are listed below in methods where appropriate.

Refer to Supplementary Materials for details of experimental procedures.

\section{In vitro experiments}

Cell line. We used PE/CA-PJ15 human oral squamous carcinoma cell line (European Collection of Cell Cultures) cultured in Iscove's modified Dulbecco's modified Eagle's medium (DMEM) (IMDM) supplemented with 10\% foetal bovine serum (Biochrom, Berlin, Germany), 1\% penicillin/streptomycin (10000 $\mathrm{U} \mathrm{ml}^{-1}$ / $10000 \mu \mathrm{g} \mathrm{ml}^{-1}$; Biochrom) and $1 \%$ of L-glutamine $200 \mathrm{~mm}$ (Biochrom) at $37^{\circ} \mathrm{C}$ in an atmosphere of $95 \%$ oxygen and $5 \% \mathrm{CO}_{2}$.

Drug administration. Curcumin (high purity; code: C7727) was dissolved in $0.5 \%$ dimethylsulphoxide (DMSO; code: 34869 ) and EtOH and sterile $\mathrm{H}_{2} \mathrm{O}(1: 1)$ and the range of administered doses was $0.5,1.0,3.37$ and $6.75 \mu \mathrm{M}$. Cisplatin (CDDP; code: P4394), dissolved in sterile saline, was administered at a dose of $1.56 \mu \mathrm{M}$. PE/CA-PJ15 cells were tested in two experimental conditions detailed in Supplementary Materials. No significant differences were observed between control (not treated) and control vehicle cells (data not shown). Cisplatin, curcumin and DMSO were purchased from Sigma-Aldrich.

Cell survival. To evaluate the toxic effect of curcumin, cisplatin and the combined drug exposure, $1.0 \times 10^{4}$ cells per well were fixed with $4 \%$ paraformaldehyde for $15 \mathrm{~min}$, washed two times in phosphate-buffered saline and then incubated in a solution containing DAPI (4',6-diamidino-2-phenylindole; 1:1000 in phosphate-buffered saline $0.1 \mathrm{M}$ ) and Triton (TX, $0.1 \%$ in phosphate-buffered saline $0.1 \mathrm{M}$ ) for $10 \mathrm{~min}$, light protected and at room temperature. Condensed cell nuclei were identified by DAPI labelling.

pSTAT3 and Nrf-2 immunofluorescence. pSTAT3 and Nrf-2 immunofluorescence were performed using primary antibodies such as rabbit anti-phospho-STAT3 (Tyr705) (Cell Signalling Technology, Boston, MA, USA) and mouse anti-Nrf-2 (Abcam, Cambidge, UK), respectively. The secondary antibodies for pSTAT3 and Nrf-2 were goat anti-rabbit 488 (Alexa Fluor) and donkey anti-mouse 546 (Alexa Fluor), respectively. DAPI counterstained the cell nuclei. Images of pSTAT3- and Nrf-2-immunolabelled specimens $(40 \times)$ were taken by the confocal laser scanning microscope (TCS-SP2; Leica Microsystem GmbH, Wezlar, Germany). Immunofluorescence was performed 24,48 and $72 \mathrm{~h}$ after treatment. However, given that no significant differences were observed among the three time points, only the results at $24 \mathrm{~h}$ are discussed.

TUNEL assay. Apoptosis was evaluated in PE-CA/PJ15 cultures with the APO-BrdU TUNEL Assay Kit (Invitrogen, Carlsbad, CA, USA) $48 \mathrm{~h}$ after treatment, according to the manufacturer's instructions, as described previously (Piacentini et al, 2008).

Western blot. PE/CA-PJ15 cells $\left(2 \times 10^{6}\right)$ were trypsinised $48 \mathrm{~h}$ after drug treatment and protein concentration was measured using a Micro BCA Kit (Pierce, Rockford, IL, USA). Protein expression was evaluated and documented using UVItec Cambridge Alliance (Cambridge, UK). The experiments were repeated three times, and an interexperiment variability of $<10 \%$ was found.

\section{In vivo experiments}

Animals. Male adult Wistar rats (200-250 g, UCSC Laboratories, Rome, Italy) were used ( 25 animals, randomised and assigned to four experimental groups as detailed in Supplementary Materials). All efforts were made to minimise animal suffering and to reduce their number, in accordance with the European Community Council Directive of 24 November 1986 (86/609/EEC). All procedures were performed in compliance with the Laboratory of 
Animal Care and Use Committee of the Catholic University, School of Medicine of Rome and were approved by the Italian Department of Health (Ministero della Salute).

Drug administration. As described previously (Fetoni et al, 2014), curcumin, dissolved in DMSO, was administered intraperitoneally at three different doses (100, 200 and $400 \mathrm{mg} \mathrm{kg}^{-1}$ body weight). Curcumin solution was injected $1 \mathrm{~h}$ before cisplatin administration and once daily for the following 3 days. A single cisplatin dose of $16 \mathrm{mg} \mathrm{kg}^{-1}$ (Fetoni et al, 2014) was delivered intraperitoneally at a rate of $8 \mathrm{ml} \mathrm{h}^{-1}$ with an infusion pump (Axon Instruments, Foster City, CA, USA) over $30 \mathrm{~min}$. The animals were hyperhydrated with saline solution (subcutaneous injection, $15 \mathrm{ml}$ daily) to limit cisplatin side effects.

\section{Auditory function evaluation}

Auditory brainstem responses: We performed auditory brainstem response $(\mathrm{ABR})$ recordings to identify the acoustic threshold of each animal for each group (Fetoni et al, 2013, 2014). ABRs were measured at low $(6 \mathrm{kHz})$, mid $(12,16$ and $20 \mathrm{kHz})$ and high $(24$ and $32 \mathrm{kHz}$ ) frequencies. In all animals, ABRs were assessed bilaterally before treatment (day 0 ) to assure normal hearing and reassessed at all time points ( 3 and 5 days from treatment onset) to evaluate the effect of treatments on hearing. PC-controlled TDT System 3 (Tucker-Davis Technologies, Alachua, FL, USA) data acquisition system with real-time digital signal processing was used for ABR recording and auditory stimulus generation (tone bursts of pure tones from 6 to $32 \mathrm{kHz}, 1 \mathrm{~ms}$ rise/fall time, $10 \mathrm{~ms}$ total duration, 20/s repetition rate). Threshold value was defined as the lowest stimulus level that yielded a repeatable waveform-based onset.

Distortion product otoacoustic emissions: To determine treatment effect on $\mathrm{OHC}$ function, distortion product otoacoustic emissions (DPOAEs) were measured unilaterally using an otoacoustic emission system (Tucker-Davis Technologies, Alachua, FL, USA). Distortion product otoacoustic emissions were recorded before, and 3 and 5 days after the onset of treatment per second.

Morphological analyses and cell viability. Rhodamine-phalloidin $(\mathrm{Rh}-\mathrm{Ph})$ staining was used to visualise the stereociliary arrays and cuticular plates of hair cells (Fetoni et al, 2014), performed at day 5 in 5 cochleae per group. All morphologic observations were performed with the confocal laser scanning system.

Nrf-2/HO-1 and pSTAT3 immunostainings. Immunostainings were performed at day 5 in cochlear cryosections to assess and quantify the endogenous antioxidant response to cisplatin-induced damage and to evaluate the effect of curcumin supplementation (Fetoni et al, 2013, 2015). Five cochleae per group were used. Images were obtained with the confocal laser scanning system. We acquired confocal Z-stacks in series of $15-20 \mu \mathrm{m}$ thick to evaluate the real extent of the nuclear and/or cytoplasmatic HO-1, Nrf2 and pSTAT3 fluorescence of the organ of Corti and SGNs (Fetoni et al, 2015). Control experiments (negative controls not shown) were performed by omitting the primary antibody during the processing of tissues randomly selected across experimental groups.

Statistical analysis. Results are presented as means \pm s.e.m., and differences were assessed using analysis of variances (ANOVAs). $P<0.05$ was considered significant.

\section{RESULTS}

\section{In vitro experiments}

Curcumin enhances cisplatin cytotoxicity in PE/CA-PJ15 cells. Tumour survival and growth of PE/CA-PJ15 cells were evaluated at
24, 48 and $72 \mathrm{~h}$ after treatment. Curcumin administration induced a cytotoxic effect in a dose-dependent manner (upper panel of Figure 1): (a) $0.5 \mu \mathrm{M}$ induced a slight cell loss that progressed over time to reach $\sim 20 \%$ of cell loss after 48 and $72 \mathrm{~h}$ of incubation, (b) $1.0 \mu \mathrm{m}$ showed a similar effect, $\sim 20 \%$ and $25 \%$ of cell loss at 48 and $72 \mathrm{~h}$, respectively, (c) with $3.37 \mu \mathrm{M}$ the cytotoxic effect increased, causing $\sim 40 \%$ of cell loss at $72 \mathrm{~h}$, (d) $6.75 \mu \mathrm{m}$ caused $\sim 60-70 \%$ of cell loss at 48 and $72 \mathrm{~h}$, respectively (Figure 1A). Moreover, low doses of curcumin affected marginally tumour proliferation at the analysed time points (Figure 1B); whereas starting from curcumin doses of $3.37-6.75 \mu \mathrm{M}$, cell proliferation was highly affected from 24 to $72 \mathrm{~h}$ (Figure 1C-E). The dosedependent effects of curcumin on PE-CA/PJ15 were also shown by signs of cell death, nuclear fragmentation and swelling, by DAPI staining (Figure 1F-J). The effects of cisplatin monotherapy and of combined regimen (cisplatin + curcumin) on PE/CA-PJ15 cells are shown in Figure 2 (upper panel), and indicate that cisplatin administration induced cell loss of $\sim 20 \%$ at $24 \mathrm{~h}$, increasing in later time points of $\sim 55 \%$ and $60 \%$ after 48 and $72 \mathrm{~h}$, respectively (Figure 2A). The adjuvant curcumin doses of 0.5 and $1.0 \mu \mathrm{M}$ determined cell loss of $\sim 30 \%, 40 \%$ and $60 \%$ at 24,48 and $72 \mathrm{~h}$, respectively (Figure $2 \mathrm{~A}$ ). This effect increased with the dose of $3.37 \mu \mathrm{m}$ causing $\sim 35 \%, 70 \%$ and $80 \%$ of cell death after 48 and $72 \mathrm{~h}$, respectively (Figure $2 \mathrm{~A}$ ). A marked cytotoxicity was observed at the adjuvant highest curcumin dose of $6.75 \mu \mathrm{M}$, causing cell loss of $\sim 55 \%$ after $24 \mathrm{~h}$ and of $\sim 70 \%$ and $90 \%$ after 48 and $72 \mathrm{~h}$, respectively (Figure $2 \mathrm{~A}$ ). With regard to cell proliferation, cisplatin arrested tumour growth (Figure $2 \mathrm{~B}-\mathrm{E}$ ), whereas the adjuvant high and medium curcumin doses decreased proliferation rate already at $24 \mathrm{~h}$ (Figure 2C-E). The adjuvant curcumin doses of 0.5 and $1.0 \mu \mathrm{M}$ did not modify the effect of cisplatin on cell proliferation (Figure 2B). In Figure 2F-K, images representative of DAPI staining illustrate the cytotoxic effects.

Curcumin enhances apoptotic activation: TUNEL assay and Bax western blotting. The analysis of DNA fragmentation in PE/CAPJ15 cells revealed low rates of apoptosis $(<5 \%)$ in control cultures (Figures $1 \mathrm{~K}, \mathrm{Q}$ and $2 \mathrm{~L}, \mathrm{R}$ ) and no significant differences were observed in cells exposed for $48 \mathrm{~h}$ to 0.5 or $1.0 \mu \mathrm{M}$ of curcumin (Figure $1 \mathrm{~L}$ and $\mathrm{M}$ ). However, a marked TUNEL labelling was observed after treatment with high and medium doses of curcumin, with an increase in the number of apoptoticpositive cells of $\sim 15 \%$ and $20 \%$, respectively (Figure 1N, O and Q). These data were also supported by western blot analysis for Bax expression. Interestingly, proapoptotic expression of $\mathrm{Bax}$ increased markedly in cells treated with medium and high doses of curcumin with respect to lower dose treatments and control cells (Figure 1P). Cisplatin monotherapy induced the activation of apoptotic processes, with $\sim 20 \%$ of TUNEL-positive cells (Figure $2 \mathrm{M}$ and $\mathrm{R}$ ). The adjuvant curcumin treatment caused an enhancement of apoptotic-positive cells in a dose-dependent manner: the highest effect was observed at 3.37 and $6.75 \mu \mathrm{M}$ doses, causing DNA fragmentation in $\sim 35-40 \%$ of cells (Figure $2 \mathrm{P}-\mathrm{R}$ ). Collectively, these results illustrate the dose-dependent proapoptotic effect of curcumin, both in the mono- and combinatorial chemotherapy.

Curcumin inhibits pSTAT3 signalling. Figure 3 shows pSTAT3 immunofluorescence data. Although in control specimens there was a clear pSTAT3 labelling in the nucleus and in the cytoplasm (Figure $3 \mathrm{~A}$ ), the fluorescence decreased progressively by increasing curcumin doses (Figure 3C, E, G and I). In cisplatin-treated cells, pSTAT3 labelling was evident in both the cytoplasm and nucleus (Figure 3B). In the combined treatment, there was a marked decrease in STAT3 phosphorylation, indicated by a change in fluorescence localisation, which remained confined inside the cytoplasm of cells (Figure 3D, F, H and J). This effect was more 
evident when medium and high doses of curcumin were used (Figure $3 \mathrm{H}$ and $\mathrm{J}$ ), as illustrated by immunofluorescence optical density analysis (Figure $3 \mathrm{U}$ ). Taken together, these results indicate that curcumin potentiates antineoplastic effect of cisplatin by acting on the inhibition of STAT3 phosphorylation: marked fluorescence intensity in the cytoplasm but absent in the nucleus indicated deficient pSTAT3 translocation.

Curcumin combinatorial treatment inhibits Nrf-2 nuclear translocation. Immunofluorescence data revealed a slight $\mathrm{Nrf}-2$ labelling in control condition (Figure 3K). PE/CA-PJ15 exposed to different doses of curcumin showed an increase in nuclear $\mathrm{Nrf}-2$ fluorescence, in a dose-dependent manner (Figure 3M, O, Q and $\mathrm{S})$. Immunofluorescence data of cisplatin monotherapy revealed a marked raise of Nrf-2 labelling, primarily cytoplasmic (Figure 4L). Interestingly, the adjuvant curcumin doses caused an increase in Nrf-2 activation that, however, remained restricted inside the cytoplasm, without translocation into the nucleus (Figure $3 \mathrm{~N}, \mathrm{P}, \mathrm{R}$ and $\mathrm{T}$ ). This effect was more evident at medium and high curcumin doses, as shown also by fluorescence quantification data (Figure $3 \mathrm{~V}$ ). Thus, these results indicate that, when administered in conjunction with cisplatin, curcumin treatment can counteract Nrf-2 activation and nuclear translocation and favours chemosensitisation.
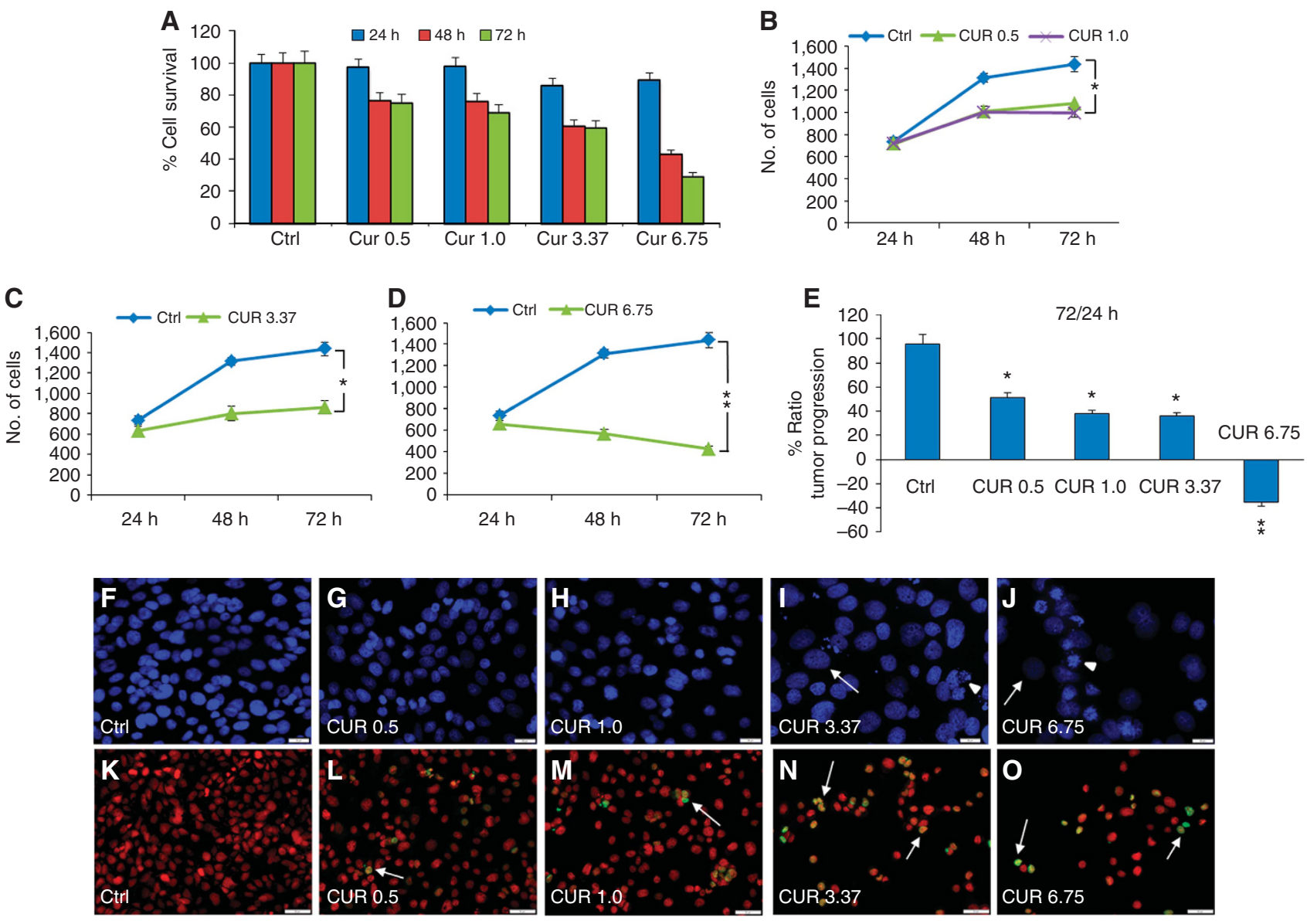

$\mathbf{P}$

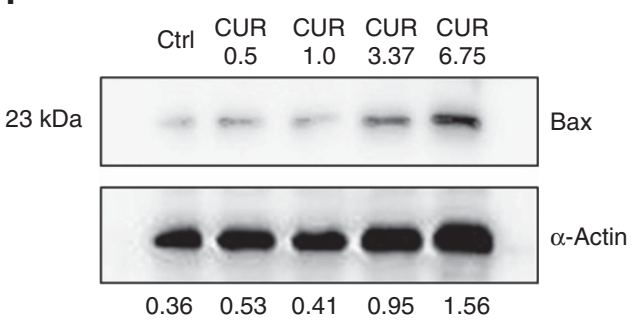

Q

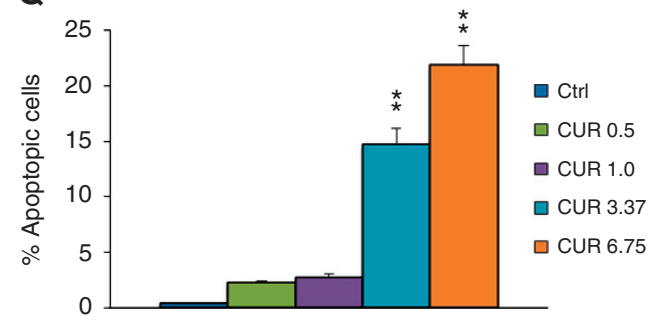

Figure 1. Curcumin influences PE/CA-PJ15 tumour progression and apoptosis. (A-D) Graphs (mean \pm s.e.m.) showing percentage of cell survival (A) and tumour progression (B-D) at 24, 48 and $72 \mathrm{~h}$ after curcumin treatment. (E) Histogram showing the magnitude of tumour progression between 24 and $72 \mathrm{~h}$, expressed as the percentage of the ratio of the number of cells counted at 72 and $24 \mathrm{~h}$. ${ }^{\star} P<0.05 ;{ }^{* \star} P<0.001$. (F-J) Representative images of DAPI-stained cells treated with curcumin: changes in morphology are indicated by arrows (swelling) and arrowheads (nuclear condensation and cellular fragmentation). Scale bar: $20 \mu \mathrm{m}$. (K-O) Representative images of terminal deoxynucleotidyl transferase dUTP nick end labeling (TUNEL) assay in PE/CA-PJ15 treated with different curcumin doses. Arrows indicative of apoptotic cells. Scale bar: $50 \mu \mathrm{m}$. (P) Western blot for Bax activation. Data are normalised to actin values. (Q) Bar graph shows the mean values (mean $\pm \mathrm{s}$.e.m.) of apoptotic cells for each condition; ${ }^{*} P<0.05 ;{ }^{\star \star} P<0.001$. Data are representative of three independent experiments; each count performed on 10 fields randomly selected for each experimental condition and each time point. 

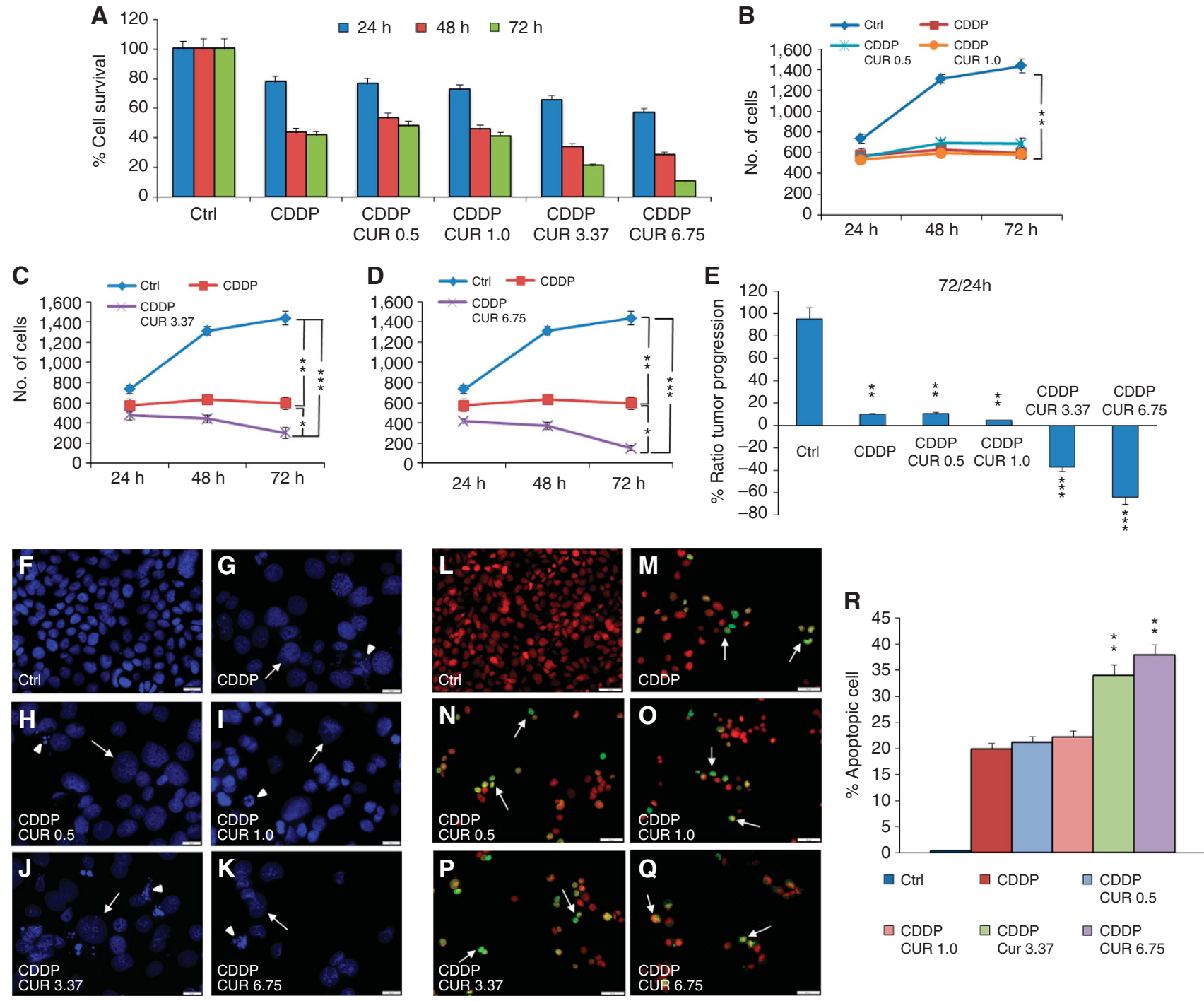

Figure 2. Curcumin increases cisplatin effect in the combined administration. (A-D) Graphs (mean \pm s.e.m.) showing percentage of cell survival (A) and proliferation (B-D) at 24,48 and $72 \mathrm{~h}$ of incubation with cisplatin and curcumin at different doses. (E) Histogram shows the tumour progression between 24 and $72 \mathrm{~h}$, expressed as a percentage of the ratio of the number of cells counted at 72 and $24 \mathrm{~h}$. ${ }^{\star} P<0.05$, ${ }^{\star *} P<0.001$ and $\star \star \star P<0.0001$. (F-K) Representative images of DAPI-stained cells; arrows and arrowheads indicate swelling and nuclear condensation/cellular fragmentation. Scale bar: $20 \mu \mathrm{m}$. (L-Q) Terminal deoxynucleotidyl transferase dUTP nick-end labeling (TUNEL) assay showing marked apoptoticpositive cells after cisplatin treatment (M) and after an adjuvant curcumin treatment ( $\mathbf{N}-\mathbf{Q}$ ). (R) Related apoptotic cell count (mean \pm s.e.m.). ${ }^{\star \star} P<0.001$. Data are representative of three independent experiments; each count performed on 10 fields randomly selected for each experimental condition and each time point.

\section{In vivo experiments: cisplatin ototoxicity}

Curcumin otoprotective effect on auditory function: $A B R$ and $D P O A E s$. ABRs were recorded in all animals before (day 0 ), and 3 and 5 days after drug treatment onset. Baseline ABR thresholds did not differ among the experimental groups, consistent with previous data (Fetoni et al, 2014). The ABR data are expressed in terms of threshold shift that represents the difference between the pre- and post-treatment values of each animal for each group. Cisplatin administration induced a threshold elevation of $\sim 35-40 \mathrm{~dB}$ at days 3 and 5, respectively, as reported previously (Fetoni et al, 2014) (Figure 4A and B). Treatment with curcumin $200 \mathrm{mg} \mathrm{kg}^{-1}$ decreased cisplatin ototoxicity of $\sim 20-25 \mathrm{~dB}$ at the same time points (Figure 4A and B). However, the lower dose of curcumin $\left(100 \mathrm{mg} \mathrm{kg}^{-1}\right)$ had no effect and the higher dose $\left(400 \mathrm{mg} \mathrm{kg}^{-1}\right)$ worsened, at day 5 , the functional damage induced by cisplatin (Figure 4A and B). Furthermore, the effect of the combined treatment on OHC function was tested by DPOAEs in all animals. Sixteen $\mathrm{kHz}$ data (frequency most affected by cisplatin administration) show a progressive decrease in amplitude in the cisplatin group, spanning from high to low DPOAE levels (Figure 4C and D). The largest changes occurred at day 5. Curcumin treatment $\left(200 \mathrm{mg} \mathrm{kg}^{-1}\right)$ significantly attenuated the decrease of DPOAE amplitude both at days 3 and 5 (Figure 4C and D). However, both low $\left(100 \mathrm{mg} \mathrm{kg}^{-1}\right)$ and high $\left(400 \mathrm{mg} \mathrm{kg}^{-1}\right)$ doses of curcumin failed to protect $\mathrm{OHC}$ function (Figure $4 \mathrm{C}$ and D).

Curcumin-protective effect in the organ of Corti: morphological analysis. Figure 4 (lower panel) shows $\mathrm{Rh}-\mathrm{Ph}$ staining and cochleogram of Ctrl, cisplatin and cisplatin + curcumin groups (200 and $400 \mathrm{mg} \mathrm{kg}^{-1}$ ). No difference was observed between cisplatin and cisplatin + curcumin $100 \mathrm{mg} \mathrm{kg}^{-1}$ groups (data not shown). Cisplatin administration induced mostly OHC loss, which was characterised by dark spots, phalangeal scars and disappearance of both cuticular plate and hair bundle in the middle and basal turns (Figure $4 \mathrm{~F}$ ). Also, OHC count showed $\sim 55 \%$ of hair cell survival in basal turn and $\sim 75 \%$ in middle turn in the cisplatin 

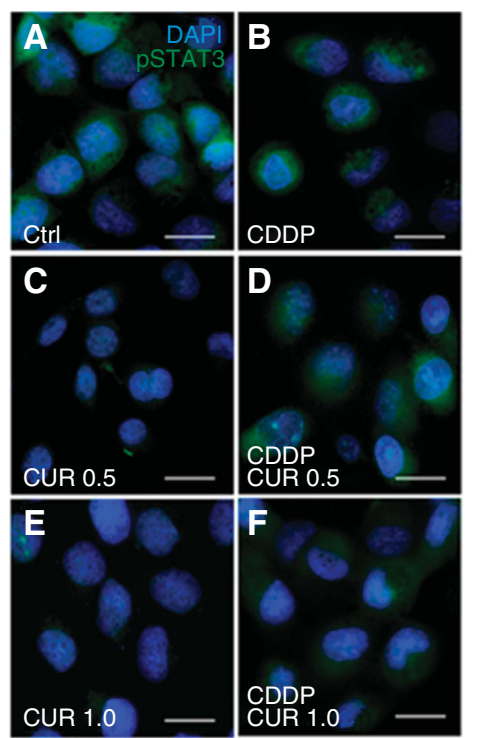

$\mathbf{F}$
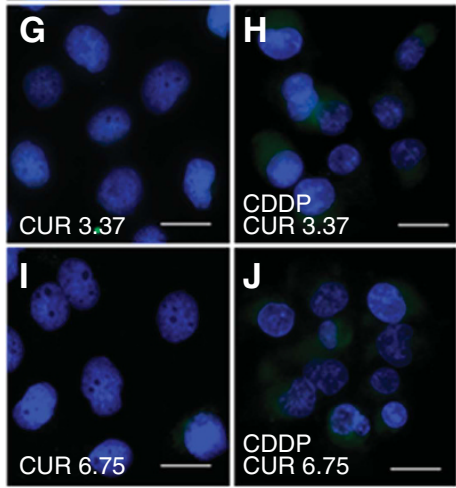
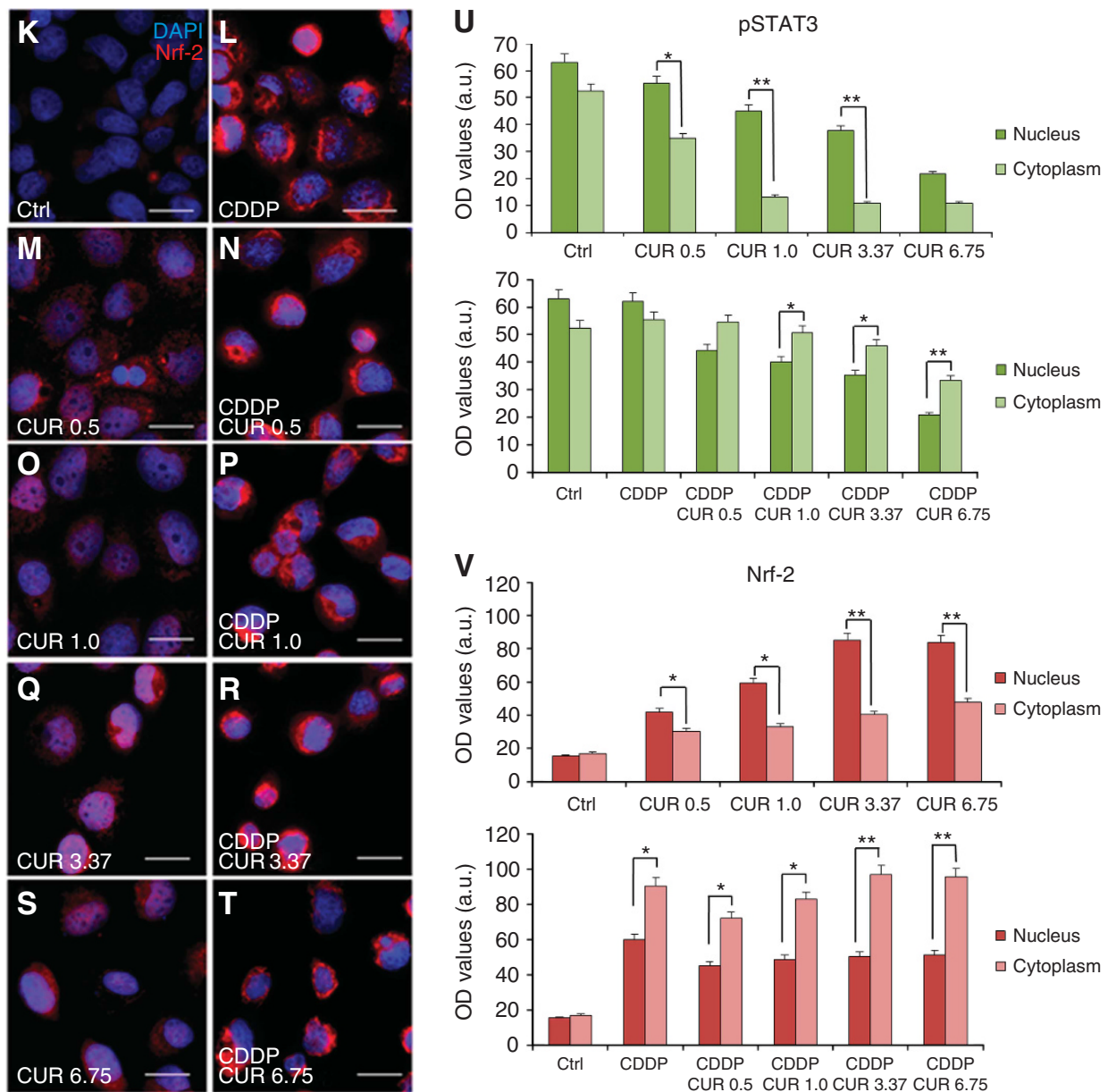

Figure 3. Curcumin prevents pSTAT3 and Nrf2 nuclear translocation when administered in conjunction with CDDP. (A-J) Representative immunofluorescence images of PE/CA-PJ15 treated with cisplatin and/or curcumin and double stained with DAPI (blue) and anti-pSTAT3 antibody (green). (K-T) Representative images of PE/CA-PJ15 cells labelled with Nrf-2 (red) and DAPI stained (blue). Scale bar: $20 \mu \mathrm{m}$. (U-V) Histograms (mean \pm s.e.m.) showing optical density quantification in the nucleus and cytoplasm of treated cells for pSTAT3 and Nrf-2 labelling, respectively. ${ }^{\star} P<0.05$; ${ }^{\star \star} P<0.001$. Data are representative of three independent experiments; each quantification performed on 10 fields randomly selected for each experimental condition and each time point.

group as compared with Ctrl (Figure 4I). In the cisplatin + curcumin $200 \mathrm{mg} \mathrm{kg}^{-1}$ group, the survival reached $\sim 85 \%$ and $95 \%$ in the same regions of basal and middle turns, respectively. Values in cisplatin + curcumin $400 \mathrm{mg} \mathrm{kg}^{-1}$ group did not differ significantly from cisplatin group: cell survival of $\sim 70 \%$ in middle turn and $\sim 50 \%$ in basal region. No significant differences were observed in the apical turn among groups.

Curcumin induces Nrf-2/HO-1 pathway activation. Figures 5 and 6 show representative Z-stack acquisitions of Nrf-2 (left panels) and HO-1 (right panels) immunostainings in high magnifications $(100 \times)$ of the organ of Corti and of SGNs, respectively. In control specimens, Nrf-2 and HO-1 labelling was slightly displaced in the cytosol in OHCs (Figure 5A and B) and in SGNs (Figure 6A and B) as shown by the XZ cross-sections (boxes $a_{1}-a_{3}$ and $b_{1}-b_{3}$ in Figures 5 and 6 ). In both organ of Corti and SGNs of cisplatin specimens, Nrf-2 (Figures 5 and 6 , boxes $c_{1}-c_{3}$ ) and HO-1 (Figures 5 and 6 , boxes $\mathrm{d}_{1}-\mathrm{d}_{3}$ ) labelling was mainly localised in the cytoplasm. No differences were observed with curcumin doses 100 and $400 \mathrm{mg} \mathrm{kg}^{-1}$ as compared with cisplatin specimens (images not shown). Treatment with curcumin $200 \mathrm{mg} \mathrm{kg}^{-1}$ induced nuclear translocation of Nrf-2, as clearly indicated by XZ cross-sections (Figures 5 and 6, boxes $\mathrm{e}_{1}-\mathrm{e}_{3}$ ). In these specimens, high $\mathrm{Nrf}-2$ fluorescence signal was detected not only in the cytoplasm but also in the nucleus, both in OHCs (Figure 5E) and in SGNs (Figure 6E). In parallel, in the same samples, we observed an overexpression of HO-1 both in the organ of Corti (Figure 5F) and in SGNs (Figure 6F), confined inside the cytoplasm (boxes $f_{1}-f_{3}$ ). Namely, the enhancement of Nrf-2 expression and its nuclear translocation, observed after curcumin administration, appears to reflect the upregulation HO-1 protein expression. Collectively, our data indicate that curcumin can activate, Nrf-2/HO-1 pathway, and potentiate this endogenous antioxidant defence mechanism against cisplatin ototoxicity.

Curcumin does not influence STAT3 phosphorylation. In control samples, STAT3 labelling was faint and mainly localised inside the cytoplasm. Cisplatin treatment did not modify pSTAT3 fluorescence, which did not translocate into the nucleus. Also, curcumin treatment at all doses did not influence STAT3 phosphorylation, which remained confined inside the cytoplasm, with no differences compared with the other groups (images not shown). Taken together, these results indicate that in our model of cisplatin-induced ototoxicity in vivo, curcumin does not act by targeting pSTAT3 signalling.

\section{DISCUSSION}

Our results indicate that curcumin enhances cisplatin activity in HNSCC cells and provides protection from cisplatin side effects in the cochlea by targeting differently the transcription factors STAT3 

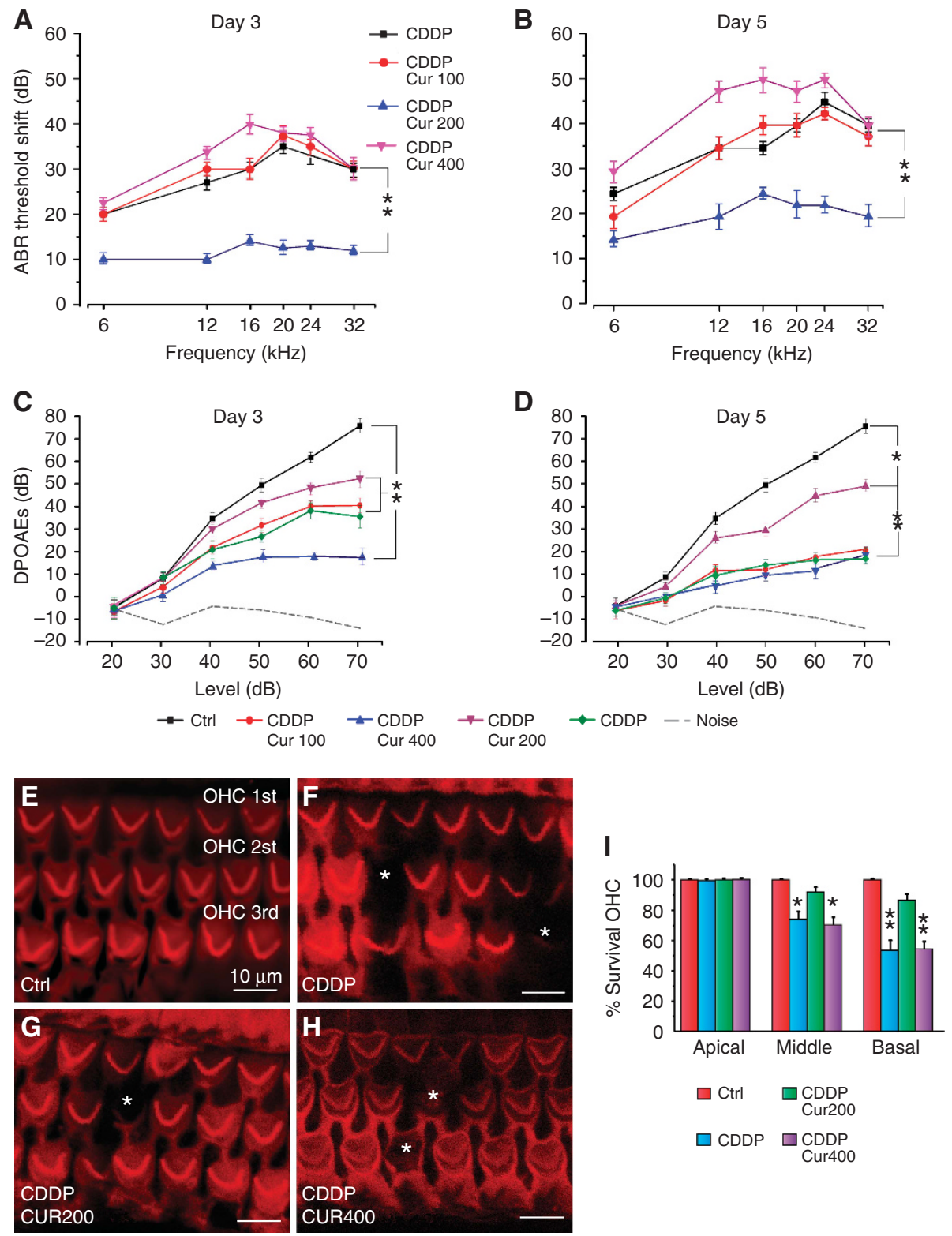

Figure 4. Curcumin attenuates the functional and morphological damage induced by CDDP in the cochlea. (A and B) Graphs show the threshold shift values in $\mathrm{dB}$ (mean \pm s.e.m.) in all experimental groups at day 3 (A) and day 5 (B) from treatment onset. (C and D) DPOAE amplitude measured at $16 \mathrm{kHz}$ at days 3 and 5, respectively. $(\mathrm{E}-\mathrm{H})$ Representative surface preparations of the organ of Corti showing Rh-Ph staining. Asterisks indicate missing OHCs. (I) Cochleogram data (means \pm s.e.m.) show significant differences among groups in the middle and basal region of the cochlea at day 5. Data are representative of three independent experiments; $n=5$ animals per group. ${ }^{\star} P<0.05 ;{ }^{\star \star} P<0.001$.

and Nrf-2. Additionally, curcumin pro-oxidant effect in cancer cells and antioxidant action in normal cisplatin-stressed cells can both be achieved by relatively low doses.

Curcumin's effect was analysed in the in vitro model of the head and neck cancer, which often demonstrates significant resistance to cisplatin, acquired through repeated treatment cycles or as an inherent characteristic of the cancer (Kelland, 2007; Abuzeid et al, 2011). Curcumin, used as monotherapy at low doses (0.5 and $1.0 \mu \mathrm{M})$, was able to induce a relatively modest antitumor effect ( $\sim 20 \%$ increase). Both the antiproliferative and cytotoxic effects increased with the medium dose $(3.37 \mu \mathrm{M})$ and were remarkably magnified at the highest dose $(6.75 \mu \mathrm{M})$ as shown in Figure 1A-E. The increasing proapoptotic activation was documented by the dose-dependent number of TUNEL-positive cells and increased Bax expression (Figure 1P). As an adjuvant to cisplatin chemotherapy, curcumin had an overall pro-oxidant activity: the antitumor effect was increased in a dose-dependent mode and the medium and high doses induced an intense cytotoxic and antiproliferative effect ( $\sim 4$-folds higher than cisplatin alone) as documented by the analysis of effect magnitude and by increased apoptosis (Figure 2E and L-R). These findings are consistent with the literature with regard to curcumin antitumor efficacy when used as monotherapy or as an adjuvant in vitro (Goel and Aggarwal, 2010; Abuzeid et al, 2011; Camacho-Alonso et al, 2013); however, translation to in vivo models and to clinical settings may pose some concerns with regard to poor bioavailability of curcumin (Cole et al, 2007; Hollborn et al, 2013). The low aqueous solubility and high degradation velocity of curcumin may indeed result in suboptimal blood concentrations to achieve the therapeutic effects (Anand et al, 2007; Naksuriya et al, 2014); however, it can be remarked that a relevant antitumor effect in vitro was observed at the low/medium doses of curcumin that could be more easily reached in vivo to obtain decreased tumour volume as shown in a curcumin-treated xenograft (Wang et al, 
Nrf-2
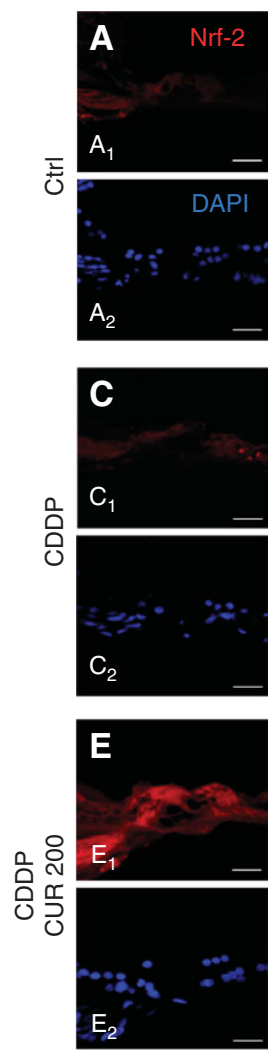
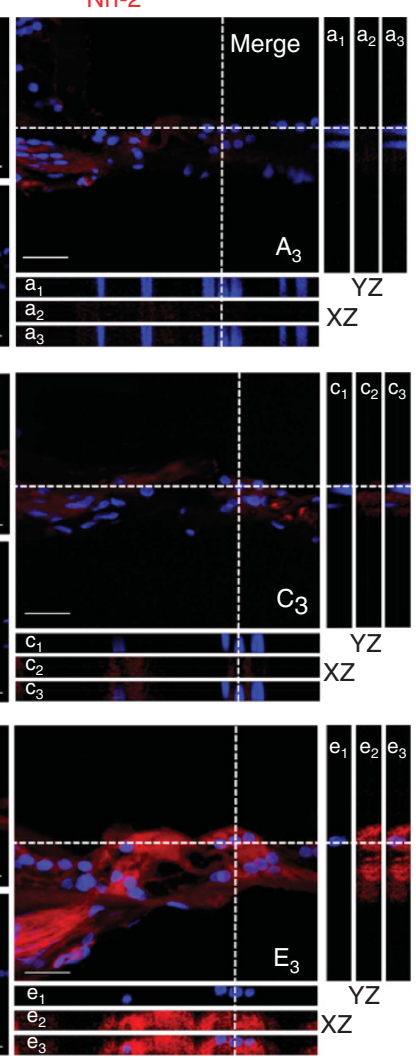

$\mathrm{HO}-1$
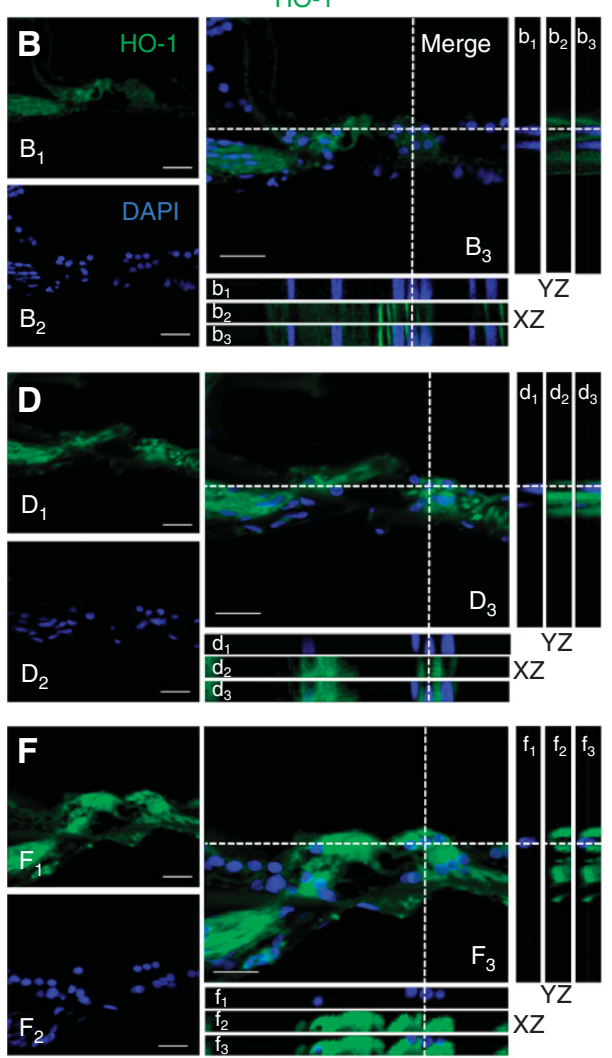

Figure 5. Curcumin potentiates Nrf2/HO-1 expression in the organ of Corti after CDDP treatment. Representative images of high magnification of the organ of Corti double stained with DAPI (blue) and Nrf2 (red, left panel) or HO-1 (green fluorescence, right panel). Merged images are shown in $A_{3}-F_{3} . X Z$ and $Y Z$ cross-sections in boxes (referred to the dashed lines) from the confocal Z-stack acquisitions show cytosolic or nuclear fluorescence signal ( $X Z$ and $Y Z$ boxes; $a_{1}, b_{1}, c_{1}, d_{1}, e_{1}, f_{1}$ : DAPI staining; $a_{2}, c_{2}, e_{2}$ : Nrf-2 fluorescence; $b_{2}, d_{2}, f_{2}:$ HO-1 fluorescence; $a_{3}, b_{3}, c_{3}, d_{3}$, $e_{3}, f_{3}$ : merge). Scale bar: $30 \mu \mathrm{m}$. Data are representative of three independent experiments; $n=5$ animals per group.

2008). In addition, the use of novel curcumin analogues with low toxicity and good bioabsorption (Kumar et al, 2014) or nanoparticle curcumin formulations (Ghalandarlaki et al, 2014; Naksuriya et al, 2014; Prasad et al, 2014; Salehi et al, 2014) offer promising approaches to overcome bioavailability characteristics and enhance the therapeutic efficacy of cisplatin in head and neck cancer patients.

The main objective of this study was, however, to get insights into the molecular targets of curcumin at different doses and we found that both pSTAT3 and Nrf-2, expressed in the control cultures, were, respectively, down- and upregulated in a dosedependent manner by curcumin monotherapy. Notably, the effect of the low doses $(0.5$ and $1.0 \mu \mathrm{M})$ on pSTAT3 was remarkable and the labelling trend was not so dissimilar as compared with the medium and high doses. As compared with controls, cisplatin did not change the nuclear and cytoplasmic pSTAT3 level that was inhibited by curcumin in the combinatory treatments even at the dose of $0.5 \mu \mathrm{M}$ (Figure 3). Signal transducer and activator of transcription 3 has been shown to be constitutively expressed in HNSCC both in vitro and in vivo (Grandis et al, 2000; Song and Grandis, 2000) and $\sim 82 \%$ of HNSCCs exhibit upregulation of STAT3 expression (Liu et al, 2008), and enhanced STAT3 expression enhances HNSCC survival (Lee et al, 2008). Overexpression of STAT3 induces tumours in nude mice (Jing and Tweardy, 2005) and interruption of STAT3 signalling impedes cancer cell growth, enhances apoptosis in HNSCC (Leeman-Neill et al, 2009) and sensitivity to cisplatin in vitro HNSCCs (Gu et al, 2010; Pan et al, 2013; Zhou et al, 2014), underlying its potential as a therapeutic target in this cancer. Signal transducer and activator of transcriptions has central roles in cancer and inflammation and signalling by various STATs, particularly STAT3, is highly interconnected with nuclear factor $-\kappa \mathrm{B}$ (NF- $\kappa \mathrm{B})$ signalling, recognised as a major pathway responsible for both inflammation-induced carcinogenesis and antitumour immunity (Karin and Greten, 2005; Sano et al, 2005; Mantovani et al, 2008; Wang et al, 2008; Lee et al, 2014). It can be speculated that, in our in vitro experiments, curcumin might interfere with STAT3 signalling even at low doses either by reducing its nuclear translocation and downstream activation of a broad array of target genes (Mali, 2015) or, possibly, by curcumin direct inhibition of NF- $\kappa \mathrm{B}$ activation that occurs mainly via I- $\kappa \mathrm{B}$ kinase (IKK)-mediated phosphorylation of inhibitory molecules (Thangapazham et al, 2006; Shishodia, 2013). Additionally, curcumin, by exerting its well-known anti-inflammatory effects, could hamper the possible cytokine-induced activation of the JAK-STAT pathway (Lai and Johnson, 2010), decreasing thus the level of cytoplasmic pSTAT3 and consequent decrease of its nuclear translocation as observed in our in vitro experiments (compare pSTAT3 cytoplasmic level of cisplatin treatment with the combined one in Figure $3 \mathrm{U}$ ). Altogether, the STAT3 curcumin targeting may represent a reliable strategy to increase the HNSCC sensitivity to cisplatin and STAT3 expression may represent an effective biomarker for predicting the response to targeting therapy (Kumar et al, 2014; Zhou et al, 2014).

The effect of curcumin on the other molecular target Nrf-2 in vitro was consistent with the literature data (Strimpakos and Sharma, 2008). Curcumin increased both cytoplasmic and nuclear Nrf-2 labelling in cancer cells, the increase was dose-dependent and the nuclear translocation reached the maximum level at $3.37 \mu \mathrm{m}$ curcumin dose. Cytoplasmic Nrf-2 was intense and its 

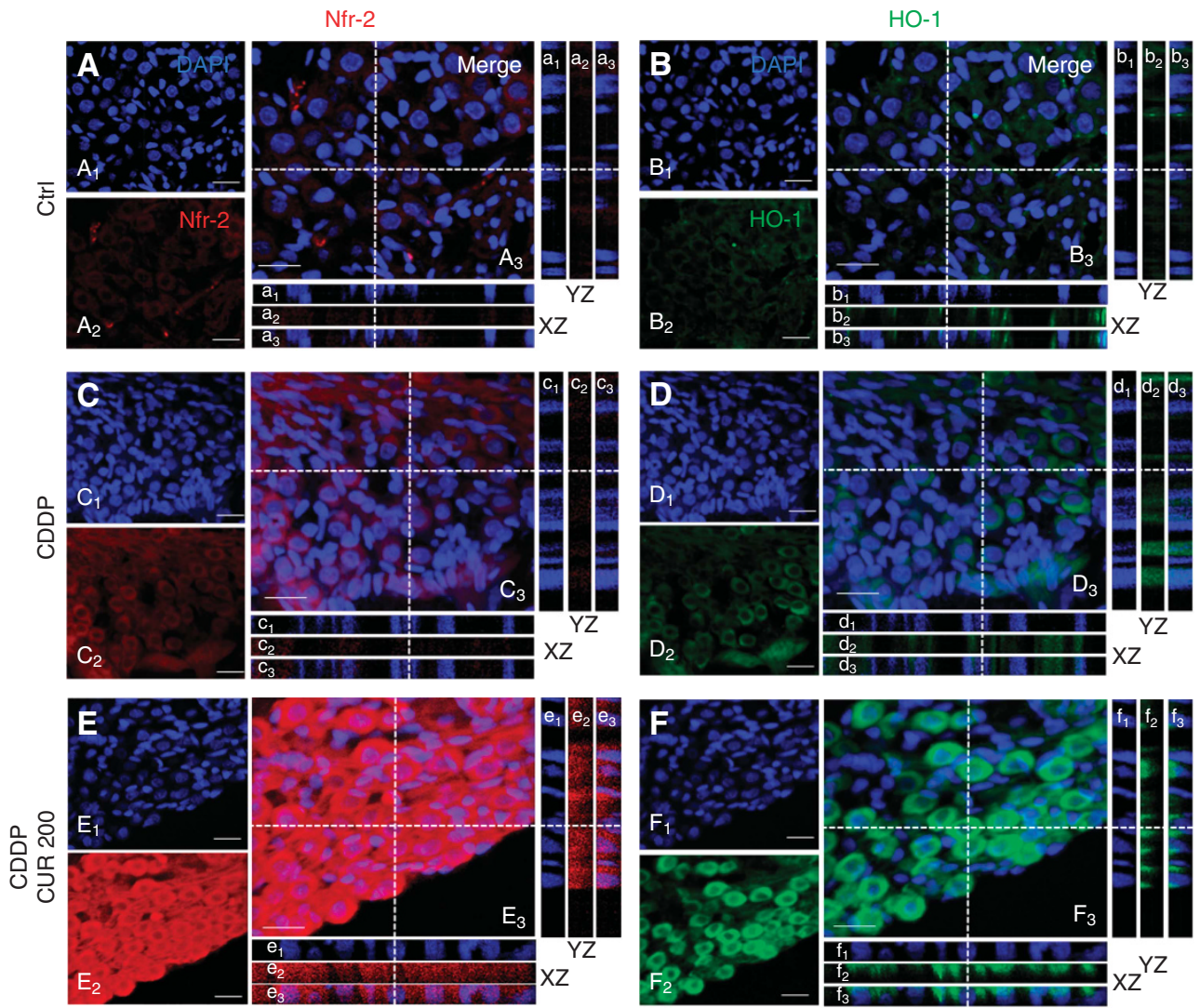

Figure 6. Curcumin enhances Nrf2/HO-1 activation in SGNs after CDDP treatment. Representative images of high magnification of SGNs immunolabelled with Nrf2 (red fluorescence, left panel), HO-1 (green fluorescence, right panel) and double stained with DAPI (blue fluorescence). Merged images are shown in $A_{3}-F_{3} . X Z$ and $Y Z$ cross-sections in boxes (referred to the dashed lines) from the confocal Z-stack acquisitions show cytosolic or nuclear fluorescence signal ( $X Z$ and $Y Z$ boxes; $a_{1}, b_{1}, c_{1}, d_{1}, e_{1}, f_{1}$ : DAPI staining; $a_{2}, c_{2}, e_{2}$ : Nrf-2 fluorescence; $b_{2}$, $d_{2}, f_{2}$ : HO-1 fluorescence; $a_{3}, b_{3}, c_{3}, d_{3}, e_{3}, f_{3}$ : merge). Scale bar: $20 \mu \mathrm{m}$. Data are representative of three independent experiments; $n=5$ animals per group.

nuclear translocation was present in cisplatin-treated cells, but, interestingly, when curcumin was combined with cisplatin treatment, cytoplasmic Nrf-2 increased with curcumin increments and the nuclear translocation decreased. Nuclear Nrf-2 labelling was faint at a combined curcumin dose of $6.75 \mu \mathrm{M}$. Again, curcumin effect was different, protranslocation in the monotherapy and translocation inhibitory in the combinatory therapy. NF-E2 p45-related factor 2, a member of the cap ' $n$ ' collar family of transcription factors, is a key component of the antioxidant response element (ARE)-mediated induction of phase 2-detoxifying and antioxidant enzymes (Lee et al, 2014). NF-E2 p45-related factor 2 is inactive in normal physiologic conditions because of its binding to the cytosolic protein Keap1. Redox stimulation causes activation of Nfr-2 and its consequent translocation to the nucleus, where it binds to ARE. Curcumin not only promotes inactivation of the Nrf2-Keap1 complex leading to increased Nrf-2 binding to AREs but it also stimulates HO-1 gene activity (Dinkova-Kostova et al, 2002; Strimpakos and Sharma, 2008; Shen et al, 2015). The Nrf2/ARE system is present both in healthy tissues, where it is involved in defence against chemical stress caused by potentially toxic compounds, and in cancer cells, where it accounts for the poor response to antitumor drugs (Hayes and McMahon, 2009; Tew and Townsend, 2012). Increased Nrf-2 expression has been extensively studied in patients with several malignancies, including head and neck cancer (Stacy et al, 2006; Huang et al, 2013). In these patients, Nrf-2 expression is significantly correlated with increased proliferation and treatment resistance to cisplatin, seemingly through the induction of antioxidant genes (Yang et al, 2011). Cisplatin resistance is a major factor in disease relapse, and the Nrf-2 translocation inhibitory effect of curcumin as an adjuvant agent to cisplatin in our in vitro experiments appears pertinent to a tumour chemosensitisation effect. Similarly and consistent with the literature (Langer et al, 2013; Waissbluth and Daniel, 2013; Fetoni et al, 2014), the cisplatin-induced redox-based modifications detected in our in vivo study of the organ of Corti determined the expression/activity of the transcription factor $\mathrm{Nrf}-2$ and the consequent upregulation of the antioxidant defence system, HO-1. On the contrary, the cisplatin adverse effects in the cochlea were inhibited when curcumin was coadministered: hearing loss was decreased, apoptosis inhibited and Nrf-2 translocation and HO-1 labelling increased. This effect in vivo was present at the medium curcumin dose, whereas lower or higher doses were ineffective or detrimental, data consistent with a previous work and the potential hormetic activity of curcumin (Calabrese et al, 2008; Fetoni et al, 2014). Remarkably, in normal cells undergoing cisplatin insult, curcumin as an adjuvant to cisplatin increases Nrf-2 activation/translocation and its downstream transcription of antioxidant genes, providing thus protection against the oxidative stress. By contrast, in cancer cells curcumin combined to cisplatin inhibits Nrf-2 translocation, providing thus sensitisation to tumour oxidative stress. The different response to curcumin of cancer and normal cells during chemotherapy may depend on a combination of factors, including the metabolism of curcumin in those cells, baseline levels of stress and their capacities for mitigating oxidative stress as reported recently for a synthetic small molecule with cancer-selective antiproliferative and cytotoxic activity (Salipur et al, 2014).

Collectively, curcumin has demonstrated significant properties in the attenuation of all stages of tumour progression (survival, proliferation) and, by targeting pSTAT3 and Nrf-2 signalling 
pathways, provides chemosensitisation to cisplatin and protection from its adverse effects. In the perspective of a personalised approach of cancer therapy, the illustrated beneficial effects of curcumin as an adjuvant agent to cisplatin offer strong preliminary data for the justification of clinical studies in humans, possibly by using novel curcumin drug delivery systems.

\section{ACKNOWLEDGEMENTS}

This work was supported by 'Fondi di Ateneo' from the Catholic University to DT; 'Ricerca Finalizzata National Grant' to ARF and by 'PRIN National Grant' to GP. Confocal analysis was performed at the 'Labcemi' facility of the same university.

\section{CONFLICT OF INTEREST}

The authors declare no conflict of interest.

\section{REFERENCES}

Abuzeid WM, Davis S, Tang AL, Saunders L, Brenner JC, Lin J, Fuchs JR, Light E, Bradford CR, Prince ME, Carey TE (2011) Sensitization of head and neck cancer to cisplatin through the use of a novel curcumin analog. Arch Otolaryngol Head Neck Surg 137(5): 499-507.

Aggarwal S, Takada Y, Singh S, Myers JN, Aggarwal BB (2004) Inhibition of growth and survival of human head and neck squamous cell carcinoma cells by curcumin via modulation of nuclear factor-kappaB signalling. Int $J$ Cancer 111(5): 679-692.

Anand P, Kunnumakkara AB, Newman RA, Aggarwal BB (2007) Bioavailability of curcumin: problems and promises. Mol Pharmacol 4(6): 807-818.

Armstrong DK, Bundy B, Wenzel L, Huang HQ, Baergen R, Lele S, Copeland LJ, Walker JL, Burger RA. Gynecologic Oncology Group (2006) Intraperitoneal cisplatin and paclitaxel in ovarian cancer. N Engl J Med 354(1): 34-43.

Berndtsson M, Hagg M, Panaretakis T, Havelka AM, Shoshan MC, Linder S (2007) Acute apoptosis by cisplatin requires induction of reactive oxygen species but is not associated with damage to nuclear DNA. Int J Cancer 120: $175-180$.

Calabrese V, Bates TE, Mancuso C, Cornelius C, Ventimiglia B, Cambria MT, Di Renzo L, De Lorenzo A, Dinkova-Kostova AT (2008) Curcumin and the cellular stress response in free radical-related diseases. Mol Nutr Food Res 52(9): 1062-1073.

Camacho-Alonso F, López-Jornet P, Tudela-Mulero MR (2013) Synergic effect of curcumin or lycopene with irradiation upon oral squamous cell carcinoma cells. Oral Dis 19: 465-472.

Cole GM, Teter B, Frautschy SA (2007) Neuroprotective effects of curcumin. Adv Exp Med Biol 595: 197-212.

Cullen KJ, Newkirk KA, Schumaker LM, Aldosari N, Rone JD, Haddad BR (2003) Glutathione S-transferase pi amplification is associated with cisplatin resistance in head and neck squamous cell carcinoma cell lines and primary tumors. Cancer Res 63(23): 8097-8102.

Demirovic D, Rattan SI (2013) Establishing cellular stress response profiles as biomarkers of homeodynamics, health and hormesis. Exp Gerontol 48(1): 94-98.

Dinkova-Kostova AT, Holtzclaw WD, Cole RN, Itoh K, Wakabayashi N, Katoh Y, Yamamoto M, Talalay P (2002) Direct evidence that sulfhydryl groups of Keap1 are the sensors regulating induction of phase 2 enzymes that protect against carcinogens and oxidants. Proc Natl Acad Sci USA 99(18): 11908-11913.

Fetoni AR, De Bartolo P, Eramo SL, Rolesi R, Paciello F, Bergamini C, Fato R, Paludetti G, Petrosini L, Troiani D (2013) Noise-induced hearing loss (NIHL) as a target of oxidative stress-mediated damage: cochlear and cortical responses after an increase in antioxidant defence. $J$ Neurosci 33(9): 4011-4023.

Fetoni AR, Eramo SL, Paciello F, Rolesi R, Podda MV, Troiani D, Paludetti G (2014) Curcuma longa (curcumin) decreases in vivo cisplatin-induced ototoxicity through heme oxygenase-1 induction. Otol Neurotol 35(5): e169-e177.
Fetoni AR, Paciello F, Rolesi R, Eramo SL, Mancuso C, Troiani D, Paludetti G (2015) Rosmarinic acid up-regulates the noise-activated Nrf2/HO-1 pathway and protects against noise-induced injury in rat cochlea. Free Radic Biol Med 85: 269-281.

Galluzzi L, Senovilla L, Vitale I, Michels J, Martins I, Kepp O, Castedo M, Kroemer G (2012) Molecular mechanisms of cisplatin resistance. Oncogene 31(15): 1869-1883.

Ghalandarlaki N, Alizadeh AM, Ashkani-Esfahani S (2014) Nanotechnologyapplied curcumin for different diseases therapy. Biomed Res Int 2014: 394264.

Goel A, Aggarwal BB (2010) Curcumin, the golden spice from Indian saffron, is a chemosensitizer and radiosensitizer for tumors and chemoprotector and radioprotector for normal organs. Nutr Cancer 62(7): 919-930.

Grandis JR, Drenning SD, Zeng Q, Watkins SC, Melhem MF, Endo S, Johnson DE, Huang L, He Y, Kim JD (2000) Constitutive activation of Stat3 signalling abrogates apoptosis in squamous cell carcinogenesis in vivo. Proc Natl Acad Sci USA 97(8): 4227-4232.

Gu F, Ma Y, Zhang Z, Zhao J, Kobayashi H, Zhang L, Fu L (2010) Expression of Stat 3 and Notch1 is associated with cisplatin resistance in head and neck squamous cell carcinoma. Oncol Rep 23(3): 671-676.

Hayes JD, McMahon M (2009) NRF2 and KEAP1 mutations: permanent activation of an adaptive response in cancer. Trends Biochem Sci 34(4): 176-188.

Hollborn M, Chen R, Wiedemann P, Reichenbach A, Bringmann A, Kohen L (2013) Cytotoxic effects of curcumin in human retinal pigment epithelial cells. PLoS One 8(3): e59603.

Huang CF, Zhang L, Ma SR, Zhao ZL, Wang WM, He KF, Zhao YF, Zhang WF, Liu B, Sun ZJ (2013) Clinical significance of Keap1 and Nrf2 in oral squamous cell carcinoma. PLoS One 8(12): e83479.

Jacobs C, Lyman G, Velez-García E, Sridhar KS, Knight W, Hochster H, Goodnough LT, Mortimer JE, Einhorn LH, Schacter L (1992) A phase III randomized study comparing cisplatin and fluorouracil as single agents and in combination for advanced squamous cell carcinoma of the head and neck. J Clin Oncol 10(2): 257-263.

Jing N, Tweardy DJ (2005) Targeting Stat3 in cancer therapy. Anticancer Drugs 16(6): 601-607.

Johnston PA, Grandis JR (2011) STAT3 signaling: anticancer strategies and challenges. Mol Interv 11(1): 18-26.

Karin M, Greten F (2005) NF-kappaB: linking inflammation and immunity to cancer development and progression. Nat Rev Immunol 5(10): 749-759.

Kelland L (2007) The resurgence of platinum-based cancer chemotherapy. Nat Rev Cancer 7(8): 573-584.

Kumar B, Yadav A, Hideg K, Kuppusamy P, Teknos TN, Kumar P (2014) A novel curcumin analog (H-4073) enhances the therapeutic efficacy of cisplatin treatment in head and neck cancer. PLoS One 9(3): e93208.

Lai SY, Johnson FM (2010) Defining the role of the JAK-STAT pathway in head and neck and thoracic malignancies: implications for future therapeutic approaches. Drug Resist Updat 13(3): 67-78.

Langer T, Zehnhoff-Dinnesen A, Radtke S, Meitert J, Zolk O (2013) Understanding platinum-induced ototoxicity. Trends Pharmacol Sci 34(8): 458-469.

Lee JH, Khor TO, Shu L, Su ZY, Fuentes F, Kong AN (2013) Dietary phytochemicals and cancer prevention: Nrf2 signaling, epigenetics, and cell death mechanisms in blocking cancer initiation and progression. Pharmacol Ther 137(2): 153-171.

Lee TL, Yeh J, Friedman J, Yan B, Yang X, Yeh NT, Van Waes C, Chen Z (2008) A signal network involving coactivated NFkappaB and STAT3 and altered p53 modulates BAX/BCL-XL expression and promotes cell survival of head and neck squamous cell carcinomas. Int J Cancer 122(9): 1987-1998.

Leeman-Neill RJ, Wheeler SE, Singh SV, Thomas SM, Seethala RR, Neill DB, Panahandeh MC, Hahm ER, Joyce SC, Sen M, Cai Q, Freilino ML, Li C, Johnson DE, Grandis JR (2009) Guggulsterone enhances head and neck cancer therapies via inhibition of signal transducer and activator of transcription-3. Carcinogenesis 30(11): 1848-1856.

Liu B, Ren Z, Shi Y, Guan C, Pan Z, Zong Z (2008) Activation of signal transducers and activators of transcription 3 and overexpression of its target gene CyclinD1 in laryngeal carcinomas. Laryngoscope 118(11): 1976-1980.

Mali SB (2015) Review of STAT3 (Signal Transducers and Activators of Transcription) in head and neck cancer. Oral Oncol 51(6): 565-569.

Mantovani A, Allavena P, Sica A, Balkwill F (2008) Cancer-related inflammation. Nature 454(7203): 436-444. 
Naksuriya O, Okonogi S, Schiffelers RM, Hennink WE (2014) Curcumin nanoformulations: a review of pharmaceutical properties and preclinical studies and clinical data related to cancer treatment. Biomaterials 35(10): 3365-3383.

Pan Y, Zhou F, Zhang R, Claret FX (2013) Stat3 inhibitor Stattic exhibits potent antitumor activity and induces chemo- and radio-sensitivity in nasopharyngeal carcinoma. PLoS One 8(1): e54565.

Piacentini R, Ripoli C, Leone L, Misiti F, Clementi ME, D’Ascenzo M, Giardina B, Azzena GB, Grassi C (2008) Role of methionine 35 in the intracellular $\mathrm{Ca}^{2+}$ homeostasis dysregulation and $\mathrm{Ca}^{2+}$-dependent apoptosis induced by amyloid beta-peptide in human neuroblastoma IMR32 cells. J Neurochem 107(4): 1070-1082.

Prasad S, Tyagi AK, Aggarwal BB (2014) Recent developments in delivery, bioavailability, absorption and metabolism of curcumin: the golden pigment from golden spice. Cancer Res Treat 46(1): 2-18.

Rybak LP, Mukherjea D, Jajoo S, Ramkumar V (2009) Cisplatin ototoxicity and protection: clinical and experimental studies. Tohoku J Exp Med 219(3): 177-186.

Salehi P, Akinpelu OV, Waissbluth S, Peleva E, Meehan B, Rak J, Daniel SJ (2014) Attenuation of cisplatin ototoxicity by otoprotective effects of nanoencapsulated curcumin and dexamethasone in a guinea pig model. Otol Neurotol 35(7): 1131-1139.

Salipur FR, Reyes-Reyes EM, Xu B, Hammond GB, Bates PJ (2014) A novel small molecule that induces oxidative stress and selectively kills malignant cells. Free Radic Biol Med 68: 110-121.

Sano S, Chan KS, Kira M, Kataoka K, Takagi S, Tarutani M, Itami S, Kiguchi K, Yokoi M, Sugasawa K, Mori T, Hanaoka F, Takeda J, Di Giovanni J (2005) Signal transducer and activator of transcription 3 is a key regulator of keratinocyte survival and proliferation following UV irradiation. Cancer Res 65(13): 5720-5729.

Shen T, Jiang T, Long M, Chen J, Ren D, Wong PK, Chapman E, Zhou B, Zhang DD (2015) A curcumin derivative that inhibits vinyl carbamateinduced lung carcinogenesis via activation of the Nrf2 protective response. Antioxid Redox Signal 23(8): 651-664.

Shishodia S (2013) Molecular mechanisms of curcumin action: gene expression. Biofactors 39(1): 37-55.

Singer E, Judkins J, Salomonis N, Matlaf L, Soteropoulos P, McAllister S, Soroceanu L (2015) Reactive oxygen species-mediated therapeutic response and resistance in glioblastoma. Cell Death Dis 15(6): e1601.
Song JI, Grandis JR (2000) STAT signaling in head and neck cancer. Oncogene 19(21): 2489-2495.

Stacy DR, Ely K, Massion PP, Yarbrough WG, Hallahan DE, Sekhar KR, Freeman ML (2006) Increased expression of nuclear factor E2 p45-related factor 2 (NRF2) in head and neck squamous cell carcinomas. Head Neck 28(9): 813-818.

Strimpakos AS, Sharma RA (2008) Curcumin: preventive and therapeutic properties in laboratory studies and clinical trials. Antioxid Redox Signal 10(3): 511-545.

Tew KD, Townsend DM (2012) Glutathione-s-transferases as determinants of cell survival and death. Antioxid Redox Signal 17(12): 1728-1737.

Thangapazham RL, Sharma A, Maheshwari RK (2006) Multiple molecular targets in cancer chemoprevention by curcumin. AAPS J 8(3): E443-E449.

Waissbluth S, Daniel SJ (2013) Cisplatin-induced ototoxicity: transporters playing a role in cisplatin toxicity. Hear Res 299: 37-45.

Wang D, Veena MS, Stevenson K, Tang C, Ho B, Suh JD, Duarte VM, Faull KF, Mehta K, Srivatsan ES, Wang MB (2008) Liposome-encapsulated curcumin suppresses growth of head and neck squamous cell carcinoma in vitro and in xenografts through the inhibition of nuclear factor kappaB by an AKTindependent pathway. Clin Cancer Res 14(19): 6228-6236.

Wondrak GT (2009) Redox-directed cancer therapeutics: molecular mechanisms and opportunities. Antioxid Redox Signal 11: 3013-3069.

Yang H, Wang W, Zhang Y, Zhao J, Lin E, Gao J, He J (2011) The role of NFE2-related factor 2 in predicting chemoresistance and prognosis in advanced non-small-cell lung cancer. Clin Lung Cancer 12(3): 166-171.

Yu H, Lee H, Herrmann A, Buettner R, Jove R (2014) Revisiting STAT3 signalling in cancer: new and unexpected biological functions. Nat Rev Cancer 14(11): 736-746.

Zhou H, Beevers CS, Huang S (2011) The targets of curcumin. Curr Drug Targets 12(3): 332-347.

Zhou X, Ren Y, Liu A, Jin R, Jiang Q, Huang Y, Kong L, Wang X, Zhang L (2014) WP1066 sensitizes oral squamous cell carcinoma cells to cisplatin by targeting STAT3/miR-21 axis. Sci Rep 4: 7461.

This work is published under the standard license to publish agreement. After 12 months the work will become freely available and the license terms will switch to a Creative Commons AttributionNonCommercial-Share Alike 4.0 Unported License.

Supplementary Information accompanies this paper on British Journal of Cancer website (http://www.nature.com/bjc) 